\title{
SARS Virus: The Beginning of the Unraveling of a New Coronavirus
}

\author{
Michael M.C. Lai \\ Department of Molecular Microbiology and Immunology, University of Southern California, \\ Keck School of Medicine, Los Angeles, Calif., USA, and Office of the Vice President and \\ Institute of Molecular Biology ${ }_{t}$ Academia Sinica, Nankang, Taiwan, ROC
}

\section{Key Words}

Severe acute respiratory syndrome - Coronavirus . Taxonomy - Origin - RNA - Viral proteins - Genetics . Mutations - Pathogenesis - Replication - Drug targets . Vaccines

\begin{abstract}
Severe acute respiratory syndrome (SARS) virus caused a severe outbreak in several regions of the world in 2003. The virus is a novel coronavirus, which may have an origin in wild animals such as civet cats in southern China. Its genome structure, gene expression pattern and protein profiles are similar to those of other coronaviruses. However, distinct patterns of several open reading frames in the SARS virus genome may contribute to its severe virulence. The potential mutability of the coronavirus genome may pose problems in the control of future SARS outbreaks. The mechanism of SARS pathogenesis may involve both direct viral cytocidal effects on the target cells and immune-mediated mechanisms. The life cycle of the SARS virus is largely unknown; however, based on the analogy with other coronaviruses, several potential targets for antiviral development are identified. Vaccines offer an important preventive measure for possible future recurrences of SARS, but the prospect for their development is still unknown because of the uncertainty regarding the role of immune responses in SARS
\end{abstract}

virus pathogenesis. The comparative studies of other coronaviruses offer insights into the understanding of SARS virus.

Copyright 92003 National Science Council, ROC and S. Karger AG, Basel

The identification of a novel coronavirus as the etiological agent of severe acute respiratory syndrome (SARS) has given an impulse to research on the coronavirus family, which has long been relegated to the status of a scientifically interesting but medically unimportant virus family. It is not that coronavirus has never been important; in fact, coronavirus infections of farm animals, such as pigs or chickens, are so common and devastating that vaccinations against these viruses are routinely performed. In humans, coronavirus infections are responsible for almost $20 \%$ of common colds in wintertime $[38,57]$, and the virus has been repeatedly implicated, but never confirmed as one of the causative agents of multiple sclerosis $[13,71]$. Nevertheless, the lack of a firm association of coronaviruses with any serious human illnesses had dampened the public's interest in this virus family until the sudden emergence of the SARS coronavirus [24, 41, 62], which caused the first new infectious disease of this millennium. The numerous past studies of the coronavirus family then quickly provided a blueprint for understanding the SARS virus. However, the contagiousness and high mortality rate of the SARS virus are unparalleled to

\section{KARGER}

$\mathrm{Fax}+41613061234$ E-Mail karger@karger.ch www. karger.com

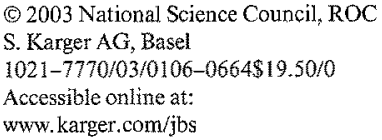


the other known human and animal coronaviruses; thus, SARS coronavirus is unique in multiple ways. The understanding of this virus, including its origin, molecular properties and pathogenesis, will be crucial for the future management of this infectious disease.

Since the studies on the SARS virus are very limited so far, this review aimed at investigating the possible properties of the virus based primarily on comparative studies of other coronaviruses.

\section{Presumptive Taxonomy}

Coronaviruses are divided into three antigenically distinct groups, which are also consistent with the genetic relatedness of these viruses [49]. Group I consists of human coronavirus 229E (HCoV-229E), porcine transmissible gastroenteritis virus (TGEV), porcine respiratory coronavirus (PRCV), feline infectious peritonitis virus (FIPV) and enteritis virus (FECoV), canine coronavirus (CCoV) and others. Group II consists of human coronavirus OC43 (HCoV-OC43), mouse hepatitis virus (MHV), bovine coronavirus $(\mathrm{BCoV})$ and others. Group III consists of avian species, including chicken infectious bronchitis virus (IBV) and turkey coronavirus (TCoV). The newly discovered SARS virus cross-reacts with antibodies of group I coronaviruses [41]. However, its genetic sequence indicates that it belongs to none of these three groups. It is of about equal distance from both groups II and III in the coronavirus family phylogenetic tree in nucleic acid or protein sequence $[41,55,66]$. A similar conclusion is reached irrespective of which viral RNA region is used for comparison. Thus, SARS virus represents a new group of coronavirus. Although this virus most likely originated from a wild animal (see next section), the SARS virus has been well adapted in humans, as evidenced by the high person-to-person transmissibility of the virus. Thus, it is most appropriately named human coronavirus SARS strain. However, its official taxonomic status remains to be decided.

\section{Origin of SARS Virus}

Since the first reported occurrence of SARS in southern China, speculation on the origin of SARS virus has largely focused on the animal species in that region. Because the genetic sequence of SARS virus is distinct and distant from that of any known coronaviruses in domestic animals, the SARS virus most likely originated from a wild animal. The search for coronaviruses in wild animals eventually turned up a coronavirus in civet cats in a market in Guangdong province. The civet cat coronavirus is very closely related to the SARS virus, with more than $99 \%$ sequence homology $[1,30 \mathrm{a}, 60]$. Recent reports indicate that $\mathrm{SARS}$ virus is distinct from the civet cat virus by limited deletions and mutations. The extent of the coronavirus infection among wild animals is not yet clear [30a]. The animal handlers appear to be at risk for the infection as a higher proportion of them have antibodies against SARS virus [30a]. However, none of these data have so far been confirmed.

Although plausible, the civet cat virus as the origin of SARS virus remains to be established. It is possible that civet cats were infected with the virus from another animal species. In either case, the critical questions are whether there is extensive horizontal transmission between animals, and whether the jump of the virus from animals to human was a rare and accidental event or portends frequent occurrences in the future. The answers to these questions will determine whether these animals are viable reservoirs for future SARS outbreaks. Thus, epidemiological studies of coronavirus infections in wild animals are critical for control of future SARS outbreaks.

Although coronaviruses, in general, infect only the animal species of their natural origin, they are known to jump to other species relatively easily. The human coronavirus OC43 is very closely related in genetic sequence to $\mathrm{BCoV}[16,36]$; thus, there is no doubt that the virus jumped from one species to the other. $\mathrm{BCoV}$ has also been reported to infect humans occasionally, causing diarrhea $[31,82]$. When MHV was passaged in tissue culture cells, the virus eventually adapted to growing in human cells $[9$, 10]. Although the mechanism of such an adaptation is not known, it is likely that it was the result of mutations in certain viral genes. Thus, there is considerable latitude in species specificity of coronaviruses. So far, SARS virus has been shown to infect humans and macaque monkeys [25]. Whether it can infect other animal species in natural infections and experimental inoculations may determine the extent of natural reservoirs for SARS virus and the feasibility of establishing animal models for it.

\section{Genome Structure}

Complete SARS virus genome sequences have been determined from more than twenty different isolates so far. These sequences showed extremely high conservation, indicating that they were all derived from a common source and did not diverge significantly during the first 


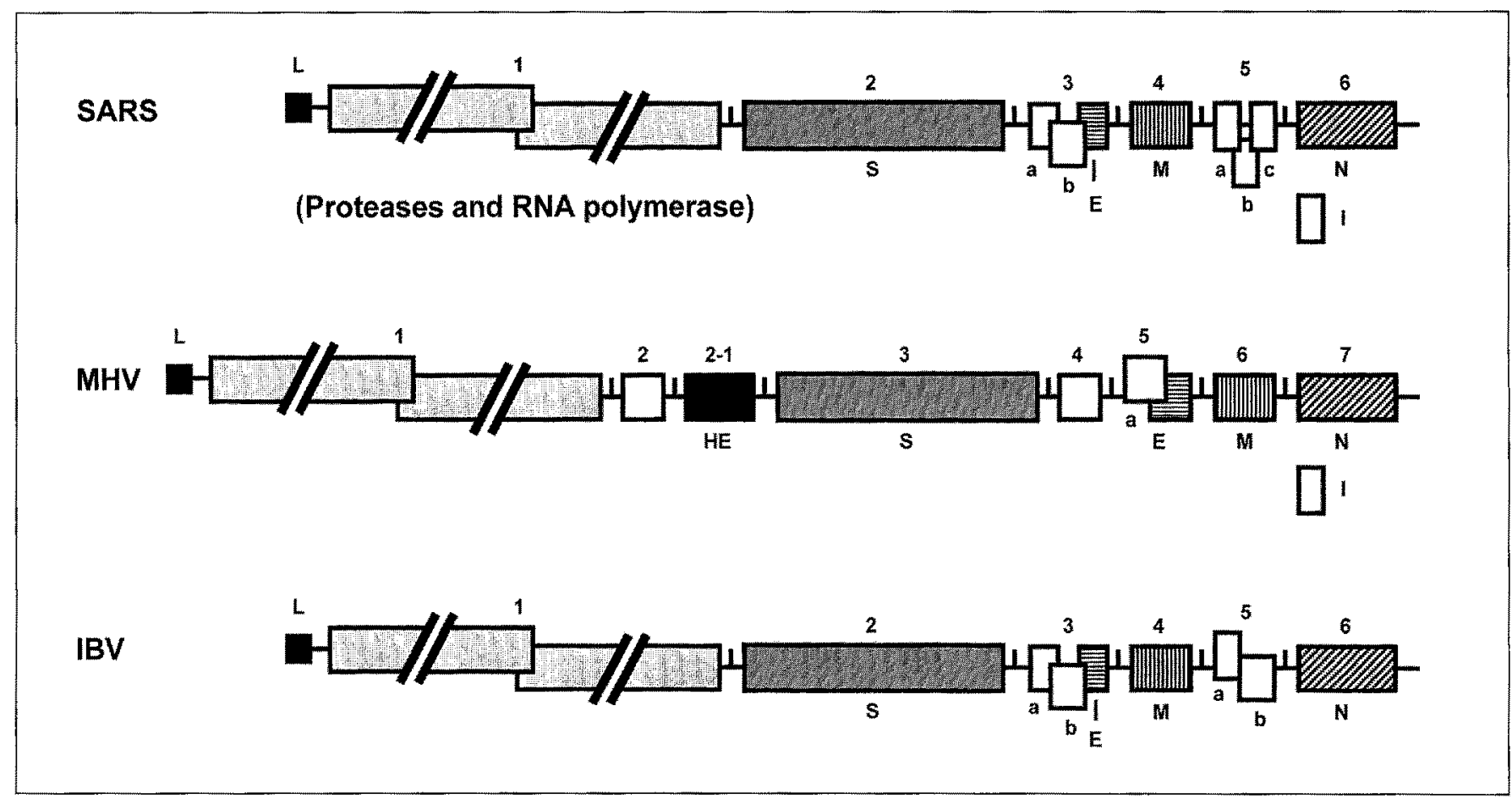

Fig. 1. Comparison of gene organization of SARS and other coronaviruses. The open boxes are ORFs of unknown functions. Gene 1 is not drawn to scale.

few months of transmission in diverse patients in different geographical areas. The viral RNA contains approximately 30,000 nucleotides, which are organized into approximately 13-15 open reading frames (ORFs), counting only those exceeding fifty amino acids in translational capacity (fig. 1) [55, 66]. Sequence comparison with those of ORFs of the other known coronaviruses reveals a similar pattern of gene organization, namely, gene 1a-1b (replicase and protease genes), spike (S), envelope (E), membrane $(\mathrm{M})$ and nucleocapsid $(\mathrm{N})$ in the order of $5^{\prime}$ to $3^{\prime}$ ends [48]. Notably, the SARS virus genome does not encode a hemagglutinin-esterase (HE) protein, which is present in most of the group II coronaviruses. Interspersed between these well-characterized genes are a series of ORFs of unknown functions. At a quick glance, the SARS virus RNA has 2 ORFs between the $S$ and $E$ genes and an additional 3-5 ORFs between the $M$ and $N$ genes. This gene organization most closely resembles that of group III coronaviruses.

In the SARS virus genome, the organization of gene $1 \mathrm{a}-1 \mathrm{~b}$, which accounts for more than two-thirds of the viral RNA, is very similar to that of the murine coronavirus MHV, except that it contains only one papain-like protease (PLpro-2) (fig. 2). Thus, the PLpro-2 of SARS virus is likely responsible for the cleavage of all the $\mathrm{N}$ terminal proteins of gene $1 \mathrm{a}$, which is normally carried out by PLpro-1 in murine coronavirus [6]. It is noted that group III coronaviruses have only one PLpro. However, the SARS virus genome has remnants of the PLpro-1 sequence; furthermore, the SARS virus has the equivalent of the leader peptide ( $\mathrm{p} 28$ ), which is missing in the group III viruses. The remaining sequences of gene $1 \mathrm{a}-1 \mathrm{~b}$ are highly conserved among all of the coronaviruses [37, 68]. Therefore, ORFs $1 \mathrm{a}$ and $1 \mathrm{~b}$ are likely translated into a polyprotein by a ribosomal frameshifting mechanism [12]. All of the potential gene products in gene $1 \mathrm{a}-1 \mathrm{~b}$ are relatively conserved between SARS and other coronaviruses. The 3C-like protease (3CLpro) is likely responsible for the cleavage of all the remaining proteins in gene $1 \mathrm{a}-1 \mathrm{~b}$ [29]. Based on the predicted cleavage site specificity, the SARS virus gene $1 \mathrm{a}-1 \mathrm{~b}$ is likely processed into thirteen final protein products. The functions of these gene products are mostly unknown; nevertheless, they are likely involved in viral RNA replication. In MHV, all the RNAnegative temperature-sensitive mutants are mapped in the genetic regions covering almost the entire gene 1 [8]. Indeed, the suppression of the SARS protease activity has an immediate inhibitory effect on viral RNA synthesis 


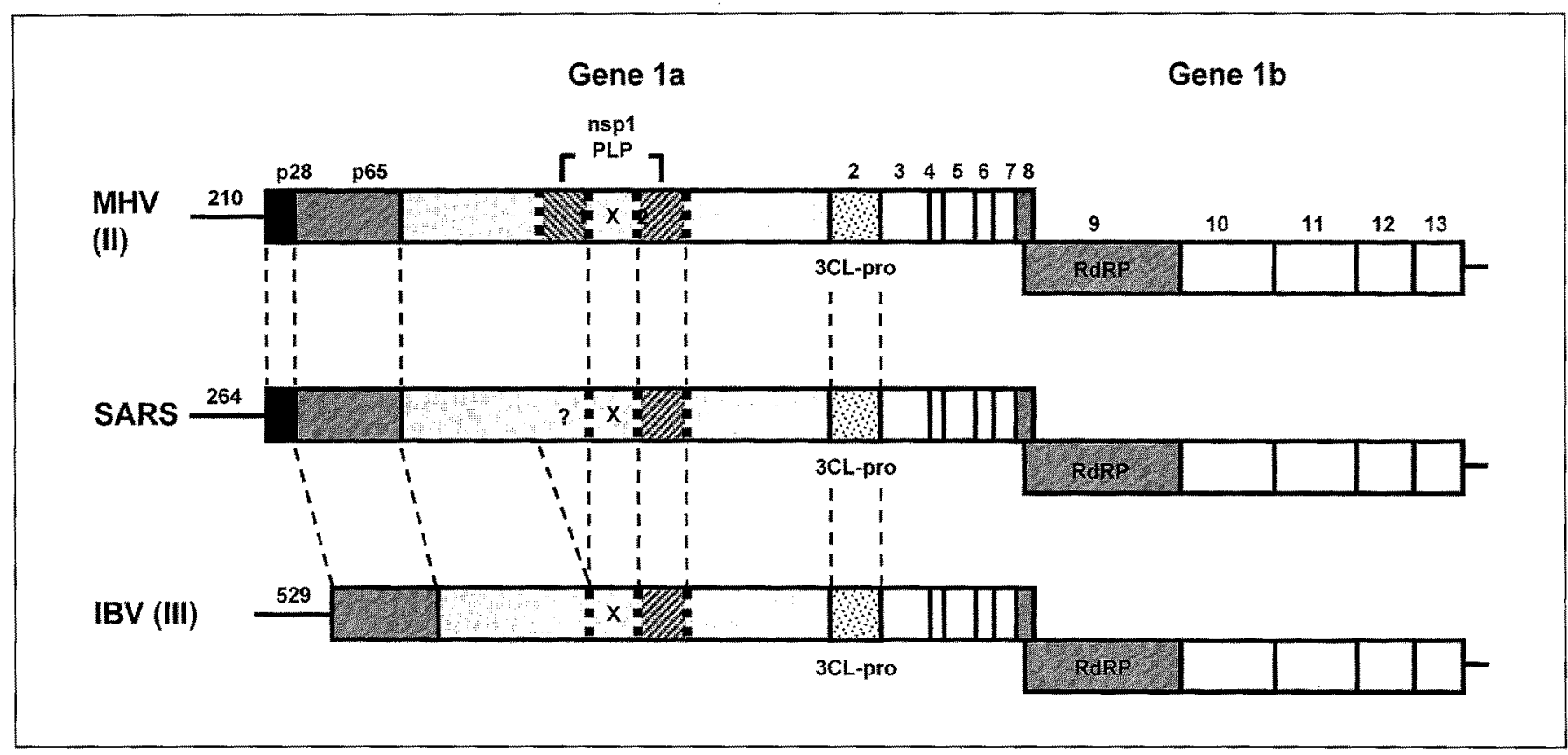

Fig. 2. Comparison of gene arrangement of genes $1 \mathrm{a}$ and $\mathrm{Ib}$. Each number on top represents the putative processing end product of the $1 \mathrm{a}-1 \mathrm{~b}$ polyprotein. Frameshifting occurs at nsp $8-9$.

[69]. It should be noted that some of the protein-processing intermediates, in addition to the final products, may also function in viral replication.

Overall, from the perspective of gene organization, the 5 -half of the SARS virus genome appears to be more closely related to group II viruses, whereas the 3 -half more closely resembles group III viruses. Therefore, SARS virus may have been derived from recombination between a group II and a group III virus. However, the published sequence analysis indicated that the entire SARS virus RNA resembled that of group II viruses; no evidence of recombination was noted $[55,66]$. Since the genetic sequence of SARS virus is approximately equidistant between group II and III viruses, the possible presence of recombination might not have been evident from sequence analysis alone. Regardless, recombination is probably not the triggering event for the jumping of the virus from animals to humans, since the recombination most likely occurred between the ancestral coronaviruses.

\section{Gene Expression}

Coronavirus genes (except for gene 1) are typically expressed from subgenomic mRNAs, which share a common leader sequence at the 5 -end, but initiate at different places from the consensus intergenic sequences or transcription regulatory sequences (TRS) in the genome and extend toward the 3 -end of the genome [48]. The transcription initiation sequences are typically rich in $\mathrm{U}, \mathrm{C}$, and $A$ residues and highly conserved in front of each gene. Each mRNA (except for the smallest) is physically polycistronic, but can be used to translate only the $5^{\prime}$-most ORF. In rare situations, several ORFs are translated from a single mRNA, e.g. mRNA 3 of IBV and mRNA 5 of MHV, by internal initiation or other mechanisms, such as an internal ribosomal entry site, which are not completely understood. These unconventional translation mechanisms are not efficient; as a result, these gene products are usually not very abundant. These ORFs typically encode viral nonstructural proteins, except for the E protein in some coronaviruses. Significantly, the ORFs between the structural protein genes are extremely heterogeneous among different coronaviruses in terms of the number of potential gene products and the method of their expression. They are not essential for viral replication in cell culture; however, recent studies suggest that deletions of these 'nonessential' ORFs could result in the reduction of viral virulence $[19,61]$. Conceivably, some of these ORFs in SARS virus could be responsible for the high virulence of this virus. A report shows that five subgenomic mRNAs were detected in Vero cells infected with the 


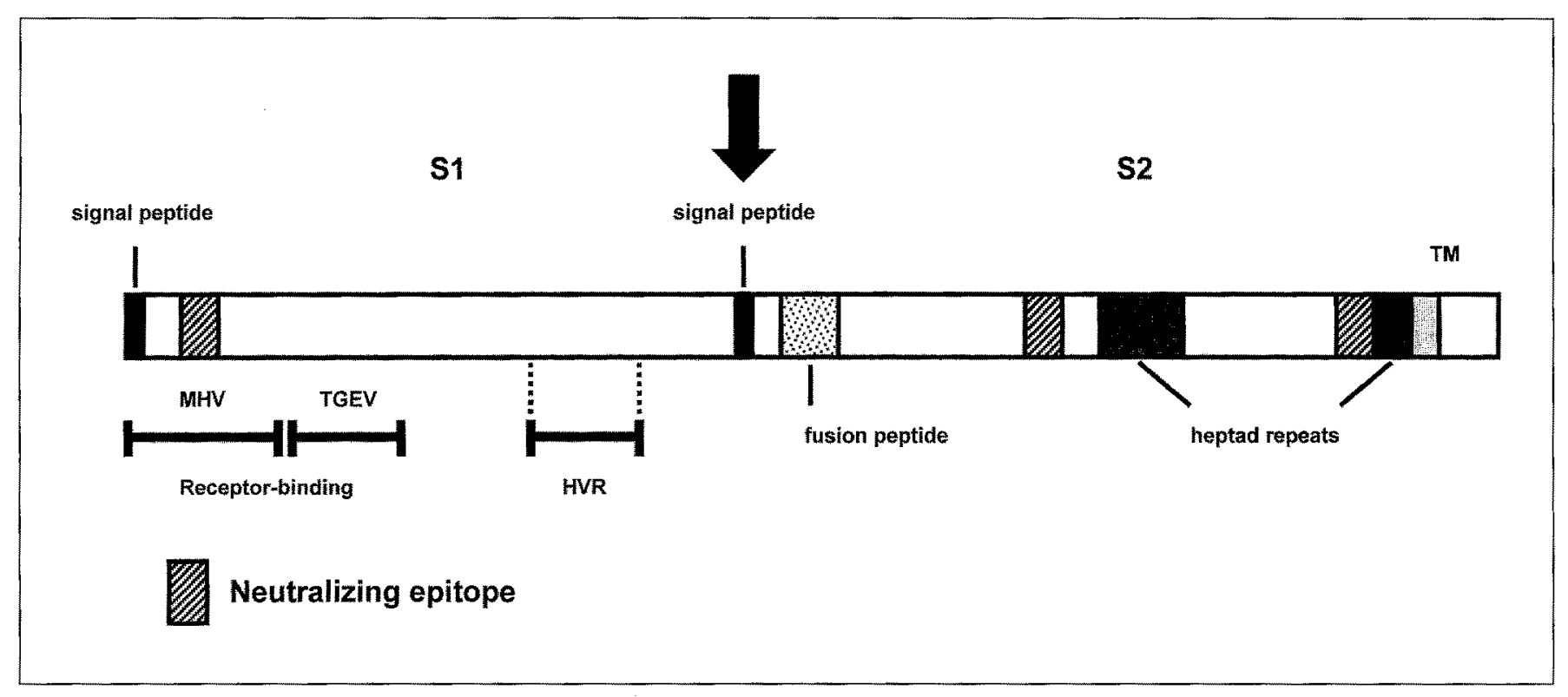

Fig. 3. The functional domains of the spike protein of the coronaviruses. The arrow indicates the potential cleavage site, which is not found in the SARS virus. HVR = Hypervariable region.

SARS virus [66]. Thus, some of the ORFs are expected to be expressed by internal initiation if they are translated at all. However, it is possible that additional subgenomic mRNAs are transcribed; the amounts of the various subgenomic mRNAs vary tremendously among different coronaviruses, depending on the strength of the transcription-start signals [48]. The less abundant subgenomic $m R N A s$ frequently were missed in northern blot analysis. Indeed, the analysis of the SARS virus genome detected many more consensus intergenic sequences (UCUAAAC and related sequences), which can potentially be used for transcription initiation $[55,66]$. A recent study detected eight subgenomic mRNA species in SARS virus-infected cells [70].

\section{Structural Proteins}

In general, coronaviruses have four envelope proteins: $\mathrm{S}, \mathrm{M}, \mathrm{E}$ and $\mathrm{HE}$. The spike protein forms the characteristic spikes that are the namesake of the virus. The $S$ protein is often cleaved into S1 and S2 domains by intra- and extracellular proteases; the cleavage often enhances the viral infectivity [28]. However, the $\mathbf{S}$ protein of some viruses, such as feline, is not cleaved, and yet the virus is fully infectious [18]. Sequence analysis of the $S$ protein of SARS virus suggests that it will not be cleaved. The spikes bind to the receptor on the target cells; the receptor-bind- ing domain is typically localized in the $\mathrm{N}$-terminus of the S1 domain [27, 42]. The spike consists of oligomeric structures, which are formed by the heptad repeats in the S2 domain (fig. 3). Typically, there are two heptad repeats in the coronavirus $\mathrm{S} 2$ proteins. S2 also contains a fusion peptide sequence, which is responsible for the fusion activity associated with coronaviruses. Significantly, the optimum $\mathrm{pH}$ for the spike-induced fusion differs from virus to virus; while most $\mathrm{MHV}$ strains cause fusion at the neutral $\mathrm{pH}$ [77], some variant viruses induce fusion at $\mathrm{pH}$ 6.5 [26]. Since the pH requirement of membrane fusion dictates the mechanism of virus entry (either by fusion at the plasma membrane or by endocytosis), different coronaviruses may use different entry mechanisms. SARS virus also causes syncytia formation in vivo, but not in the cultured Vero cells [41]. As the S protein of SARS virus possesses most of the features of the $S$ proteins of other coronaviruses, it will be interesting to know the conditions, such as protease sensitivity and $\mathrm{pH}$ dependence of membrane fusion, that enhance the SARS virus infectivity. It should be noted that both S1 and S2 contain the neutralization epitopes of MHV [48] and that there is a hypervariable region in $\mathrm{S} 1$, which is frequently mutated or deleted in the coronaviruses. Such mutations very often change the biological or pathogenic properties of the virus.

The $\mathrm{M}$ and $\mathrm{E}$ proteins are the minimum protein units for virus assembly $[11,75]$. Both are integral membrane 
proteins. M protein resides not only on the viral envelope, but in the viral internal core as well [65]. In the cells, $M$ protein is anchored in the Golgi complex, thus dictating the site of virus assembly to the ER-Golgi complex [73]. The expression of $\mathrm{M}$ and $\mathrm{E}$ proteins together is sufficient to trigger the formation of virus-like particles (VLP). When $S$ protein is coexpressed with $M$ and $E$ proteins, the $\mathrm{S}$ protein is incorporated into VLP with presumably authentic conformation. Such a VLP can infect cells [11]. Thus, these VLPs will be an excellent candidate as a potential vaccine. Intriguingly, it has recently been shown that $\mathrm{E}$ protein may not be absolutely required for viral infectivity [43]. SARS virus has comparable structural proteins.

HE protein is seen only in some group II coronaviruses; it is not required for viral infectivity even in those viruses (e.g. MHV, HCoV-OC43) that contain the HE protein. However, HE protein may be involved in the infection of $\mathrm{BCoV}$, as a monoclonal antibody against $\mathrm{HE}$ protein can inhibit $\mathrm{BCOV}$ infection [21]. The HE protein binds to certain sialic acid residues and possesses an acetyl-esterase activity. It is conceivable that $\mathrm{HE}$ protein provides the initial binding contact between the virus and the target cells; however, subsequent tight and specific binding may be mediated by the S protein. HE protein bears sequence homology with the hemagglutinin protein of influenza $C$ virus, thus prompting suggestions that recombination has taken place between an ancestral coronavirus and an influenza virus [54]. SARS virus does not encode the HE protein.

The final structural protein is $\mathrm{N}$ protein, which likely interacts with viral RNA and makes up the viral core and nucleocapsid. It is interesting to note that the coronavirus particles appear to include both an icosahedral core and an internal helical nucleocapsid [65]. $\mathrm{N}$ protein is present in both structures. SARS virus has typical N protein structural motifs, including several RNA-binding domains.

\section{Unusual Features of Coronavirus Envelope}

Coronaviruses have an envelope that reflects the lipid composition of the cellular membranes. However, remarkably, coronavirus is one of the very few enveloped viruses that are able to cause enteric infections. Thus, the viral envelope certainly can resist the harsh environment of the gastrointestinal tract, namely, the acidic environment of the stomach and the bile and lytic enzymes of the small intestines. The structural and chemical basis for such unusual resistance is not yet clear. Correspondingly,
SARS patients very often show GI symptoms, and the virus is usually detected in the stool [62]. Therefore, the envelope of SARS virus likely consists of unusual structures. Indeed, it has been shown that SARS virus can survive in diarrheal stool for as long as 4 days and on a dry surface for $24 \mathrm{~h}$ (World Health Organization Bulletin). These unusual envelope properties have implications for the control of the SARS outbreaks.

\section{The Emerging Genetics of SARS Virus}

As an RNA virus, SARS virus can be expected to undergo mutation at a very high frequency. With an estimated error frequency of $1 \times 10^{-4}$ for RNA-dependent RNA polymerases in general, the SARS virus genome can be expected to accumulate an average of three mutations per round of RNA replication. Thus, SARS virus, like all other RNA viruses, probably consists of a collection of RNA quasispecies [23]. Such a high frequency of mutation implies that the RNA viral genome is inherently limited in size. Coronaviruses are obvious aberrations. Yet, despite having an extraordinarily long RNA genome, SARS virus and other coronaviruses appear to be relatively genetically stable. To date, the predominant RNA species from different SARS patients appear to be quite homogeneous. The various SARS virus isolates from different geographical regions differ by no more than ten amino acids in the entire genome. It is not clear whether these differences confer any differences in the biological properties of the virus. Nevertheless, they allow epidemiological tracing of the virus transmission routes. It appears that two different lineages of the SARS virus can be independently traced [67]. Whether the virus will undergo a higher frequency of mutation in the future once seasonal changes occur or after specific drug treatments are introduced is an issue of concern. However, there has been no investigation of the nature of RNA quasispecies of SARS virus derived from different patients so far. Such RNA quasispecies may represent potential sources of viral divergence.

Coronaviruses have another powerful genetic means for evolution: RNA recombination, which occurs at a very high frequency [46]. In theory, recombination may not only introduce genome alterations but, paradoxically, balance the deleterious effects of mutations by removing the undesirable defects [47]. This ability may explain why coronavirus can maintain such a long RNA genome. The ability of coronaviruses to recombine may stem from the nonprocessive nature of coronavirus RNA polymerase, 
which mediates discontinuous RNA synthesis during mRNA transcription [49].

In natural infections, both mutation and recombination have been demonstrated to contribute to the evolution of the coronaviruses. Avian coronavirus IBV continues to undergo antigenic changes in the field through both mutation and recombination involving the $S$ gene. Recombination could occur between the field isolates and the vaccine strains of IBV $[44,76]$. This evolution causes problems in vaccination strategies, as multiple vaccines directed against different viral serotypes must be used simultaneously. Another example is the emergence of porcine respiratory coronavirus ( $\mathrm{PRCOV}$ ) from the enteric TGEV in Europe as well as in the US in the 1980s [50]. Again, this shift in viral tissue tropism and virulence was due to deletions and mutations in the $\mathrm{S}$ gene. This evolution turned out to be beneficial to the livestock industry because the resultant $\mathrm{PRCoV}$ is considerably less virulent than the parental TGEV and, in fact, was used as an attenuated virus vaccine for TGEV. A feline coronavirus has also been demonstrated to have undergone recombination with a canine coronavirus, resulting in changes in the biological properties of the virus [35].

The ability of the coronavirus to recombine has been utilized as a genetic tool for manipulating the coronavirus genome. Until recently it had been impossible to apply reverse genetic methods for studying coronaviruses because of the large size of its genome. Taking advantage of the ability of coronavirus to recombine with not only other coronaviruses but also viral RNA fragments, Masters and his colleagues have developed techniques to introduce mutations into $\mathrm{MHV}$ defective interfering RNA and allow it to recombine with a temperature-sensitive mutant (the mutation being in the $\mathrm{N}$ protein-coding region) of MHV [63]. By selecting wild-type viruses capable of growing at the high temperature and using other selection markers, it is now possible to engineer mutations into certain viral RNA regions or exchange certain viral genes between different coronaviruses [32]. This technique has been applied only to MHV so far. However, a flood of reports in the last 2 years has shown that full-length infectious cDNA clones can be obtained for several coronaviruses, including TGEV, MHV, HCoV-229E, PEDV and IBV $[2,14,72,81]$. These cDNA clones have added to the arsenal of coronavirus genetic tools. It is anticipated that the full-length SARS virus cDNA will be available soon. Both this cDNA and the targeted recombination approach may provide the reverse genetic tools for studying SARS virus. The temptation to manipulate the SARS virus genome will be great. However, I must add a word of caution before such attempts are made. The scientific community must be vigilant in guarding against the misuse of these genetic tools to alter the SARS virus genome or create chimeric coronaviruses involving SARS virus genes. I propose a moratorium on these types of experiments until the various concerned international communities agree upon specific guidelines. The potential for unleashing a more virulent new SARS virus is simply too onerous to be ignored.

\section{Mechanism of Viral Pathogenesis: Cytocidal vs. Immune-Mediated}

Coronaviruses, in general, cause disease by both cytocidal and immune-mediated mechanisms. Most coronavirus infections in cell culture result in lysis or apoptosis of the infected cells [53]. Furthermore, the virus causes cell fusion, resulting in the formation of cell syncytia. These cytopathic effects (CPE) are usually the results of viral replication. For example, the coronavirus mobilizes cellular vesicles to form the viral replication complex [30], which may disrupt the Golgi complex [51]. SARS virus also causes CPE in Vero cells; furthermore, it causes syncytia formation in the lung tissue, suggesting that it causes cytocidal effects. Another eerie similarity between SARS virus and other coronaviruses is their ability to induce fibrosis; e.g. certain strains of MHV cause fibrosis in the liver [22], and SARS virus causes fibrosis in the lung [58]. The $\mathrm{N}$ protein of MHV has been shown to stimulate the promoter activity of the prothrombinase gene [59], which correlates with the fibrin deposit in the liver associated with MHV infection. A similar mechanism may be involved in the fibrosis of the lung induced by SARS virus.

Immune responses also contribute to the pathogenesis of several coronaviruses. Most notably, cytotoxic T cells and cytokines play a very significant role in the neuropathology caused by MHV [56]. On the other hand, humoral antibodies are important for the disease associated with FIPV, in which certain antibodies against the viral S protein induce severe peritonitis symptoms [17, 78]. In the case of SARS, there is an occurrence of cytokine storms and accumulation of inflammatory cells, particularly macrophages in the lung, during the peak of the disease [58], suggesting that both innate and adaptive immune responses are important for the disease. Thus, the clinical management of SARS should consider not only antiviral but anti-inflammatory strategies as well.

Several viral genes are likely involved in viral pathogenesis. Most importantly, the spike protein gene affects 
viral pathogenesis not only by determining the host target cell specificity but by other mechanisms as well. As exemplified above, the emergence of the weakly virulent PRCV from the virulent enteric TGEV was the result of mutations in the $S$ gene [7]. Also, it has been shown that a single mutation in the S gene of MHV can significantly alter the tissue tropism and virulence of the virus [52].

The so-called 'non-essential ORFs' may also play a role in viral pathogenesis. These genes are not necessary for viral replication in tissue culture cells, as experimental or natural deletions of any one of these genes did not affect the ability of the virus to replicate. However, some of these deletion mutants show much lower virulence than the wild-type virus in infections in animals [19]. It is significant that SARS virus shows significant divergence of these ORFs from other coronaviruses. A preliminary report shows that the civet cat coronavirus has a 29 nucleotide deletion, which caused two non-essential ORFs to fuse into one, creating a new ORF in the SARS virus [30a]. It will be very interesting to find out if this new ORF contributes to the virulence of the SARS virus. Other viral gene products may also alter cellular responses to the viral infection. For example, M protein of TGEV can induce interferon [15], and E protein of MHV can induce apoptosis [3]. They may modulate the course of viral infection.

Another important issue in the pathogenesis of SARS virus is whether the virus can cause chronic persistent infection. This issue concerns the possible presence of chronic carriers, who may serve as the source of continuing SARS outbreaks. Although human coronaviruses typically cause short, self-limiting illnesses, most of the animal coronaviruses are known to cause persistent infection. The best studied coronavirus in this regard is feline coronavirus FECoV; infected animals can continue to shed virus for as long as 7 months after infection, even though these animals do not show symptoms [34]. TGEV also shows a similar tendency, in which the virus can be detected in the respiratory tract of the infected animals several months after infection [40,74]. MHV can persist in the central nervous system many months after intracranial inoculation [40]. Thus, the ability to persist is a common feature of most coronaviruses under some conditions. SARS virus may also have this property. So far, viral RNA reportedly has been detected in patients' stool more than 30 days after infection (World Health Organization Bulletin).

\section{The Postulated Life Cycle of SARS Virus: Potential Molecular Targets of the Antiviral Agents}

Coronavirus primarily infects the epithelial cells of the GI and respiratory tracts, but the virus can replicate in many cell types, particularly macrophages. SARS virus also infects a wide spectrum of cell types; it has been detected in the blood, lung, liver and kidney, and in various bodily secretions, including stool and urine [41]. Thus, SARS virus may induce systemic infection. The primary determinant of target cell specificity of the virus is the nature of its cellular receptors. Type I coronaviruses use aminopeptidase $\mathrm{N}$ (CD13) of various animal species as receptors in a species-specific manner [20,80], while a type II coronavirus (MHV) uses the carcinoembryonic antigen as receptor [79]. The receptors for type III viruses and SARS virus are not yet known. It should be noted that the virus easily adapts to cell lines of different animal species, probably by using other related molecules as a receptor [9]. Thus, the specificity of the spike-receptor interaction may not be very rigid. Interruption of the binding between the spike protein and the receptor will be a potential means of inhibiting viral infection.

The next step of virus infection is virus entry. The mode of virus entry for coronavirus may vary between different viruses. Although most viruses appear to enter cells by fusion at the plasma membranes, some viruses may enter cells by acidic $\mathrm{pH}$-dependent endocytosis. $\mathrm{Re}-$ gardless, the fusion activity is likely important for virus entry. Several functional domains, including the heptad repeat, which is important for oligomerization of the spike protein, the putative fusion peptide, and the receptor-binding domain of the $S$ protein, will be good targets for antivirals.

Macromolecular synthesis, including transcription, translation and protein processing, offers many potential molecular targets as well. Most notably, proteases, RNAdependent RNA polymerases (RdRP) and helicases are good targets. Unfortunately, in vitro RdRP assays are still neither efficient nor specific, precluding their use as a molecular tool for drug screening. In vitro protease assays for both 3CLpro and PLpro, in contrast, are well established $[33,83]$. The protease activity is essential for viral protein processing and RNA replication; inhibition of the protease function shuts off viral RNA synthesis instantaneously [69]. Thus, the proteases are potentially powerful targets for antivirals. Furthermore, the X-ray crystallographic structure for the 3CLpro is available [4], as is a computation model for the SARS virus 3CLpro [5]. These 
tools provide blueprints for SARS virus research and the basis for the molecular design of antivirals.

In addition, the processes of virus assembly, which likely occurs in the ER-Golgi intermediate compartment [39], and virus exit, which occurs through the cellular secretory pathway, are also potential antiviral targets. It has been known that the $\mathrm{E}$ and $\mathrm{M}$ proteins are the minimum components for virus assembly, forming VLP in the absence of other viral proteins [11,75]. The cellular machinery involved in the formation of virus particles is still not clear; it is a potential antiviral target as well.

\section{Vaccines}

The prospect for SARS vaccines is uncertain. Several potential approaches are feasible. The killed whole virus vaccine is attractive because of the availability of a robust cell culture system that yields a large quantity of virus particles. Attenuated virus vaccines are still unattainable because the parameters for virus attenuation are not yet well defined. Ultimately, the attenuation of viral virulence needs to be verified preclinically in animal models. Recombinant subunit vaccines consisting of the spike protein alone or in combination with other viral proteins can be prepared by using the recombinant proteins themselves or delivered by virus vectors or as DNA plasmids. These approaches are technically feasible. However, the timetable for the development of any of these vaccines is lengthy, and the potential success of vaccine development may be hindered by the lack of accessibility to animal models and a suitable population base for clinical trials. At the present time, the macaque monkey is an acceptable animal model. However, with the SARS epidemic virtually over worldwide, it will be difficult to test the efficacy of these vaccines. Eventually, 'ring' vaccination (vaccination of the at-risk populations around the exposed people) may have to be attempted. Nevertheless, vaccine development is clearly a top priority, as vaccines are the main weapons in the arsenal against future outbreaks, whether they are natural or man-made (i.e. bioterrorism) in origin.

A survey of the currently available animal coronavirus vaccines offers a glimpse of the potential efficacy of SARS vaccines. Live attenuated vaccines have been used effectively against IBV. Sometimes, a killed virus vaccine is used as a booster to the primary attenuated virus vaccine [45]. The drawbacks of these vaccines are that IBV exists in multiple antigenic types and that the virus undergoes frequent antigenic changes as a result of mutations and recombination. Therefore, multiple viruses of different serotypes must be used in combination vaccines to protect against most IBV serotypes. For TGEV, live attenuated virus vaccines have been used to vaccinate the adult pigs. The vulnerable piglets receive the protective antibodies through milk. Improvement in lactogenic immunity is therefore the aim of TGEV vaccine development. Killed canine coronavirus has proven to be efficacious as a vaccine experimentally [64], although it is not routinely used because of the lack of necessity.

On the other hand, feline coronavirus vaccines have been proven to be not only inefficacious; worse yet, they have been shown to lead to even more severe viral infections in the vaccinated cats [78]. Enhancement of viral infections by vaccines is probably due to the phenomenon of antibody-dependent enhancement (ADE), in which antibodies against certain epitopes of the spike protein complex with the virus particles and enhance their infectivity [17].

It is difficult to predict how the candidate SARS virus vaccines will behave. If immune response plays an important role in the pathogenesis of SARS, then an effective SARS vaccine may turn out to be as elusive as the FIPV vaccines. Similar difficulties have plagued the developments of other viral vaccines, such as dengue virus, HIV, hepatitis $\mathrm{C}$ virus.

\section{Epilogue}

SARS is the first newly emerged infectious disease in this century. It is not likely to be the last one. Even though the SARS outbreak is now under control after a devastating run of more than 6 months that affected and threatened many countries worldwide, the virus will continue to pose a threat in the near future. Because of possible human and animal reservoirs for the virus, SARS may return in the coming months or years. In the short term, the isolation and quarantine of patients and exposed individuals remain the only effective means of containing an outbreak. Valuable experience in disease control was gained from this first outbreak; thus, the future outbreaks of SARS and other emerging and re-emerging respiratory infectious diseases will likely be limited to sporadic occurrences. Hopefully, intensive studies of the SARS virus in the near future will provide sufficient understanding of its molecular biology and mechanism of pathogenesis to enable the development of antiviral drugs and vaccines. Only then can we effectively control the disease. 


\section{References}

1 Abbott A. Pet theory comes to the fore in fight against SARS. Nature 423:576;2003.

2 Almazan $F$, Gonzalez $\mathrm{M}$, Penzes Z, Izeta A, Calvo E, Plana-Duran J, Enjuanes L. Engineering the largest RNA virus genome as an infectious bacterial artificial chromosome. Proc Natl Acad Sci USA 97:5516-5521;2000.

3 An S, Chen C-J, Yu X, Leibowitz JL, Makino $S$. Induction of apoptosis in murine coronavirus-infected cultured cells and demonstration of E protein as an apoptosis inducer. J Virol 73: 7853-7859;1999.

4 Anand K, Palm GJ, Mesters JR, Siddell SG, Ziebuhr J, Hilgenfeld R. Structure of coronavirus main proteinase reveals combination of a chymotrypsin fold with an extra alpha-helical domain. EMBO I 21:3213-3224;2002.

5 Anand K, Ziebuhr J, Wadhwani P, Mesters JR, Hilgenfeld $R$. Coronavirus main proteinase (3CLpro) structure: basis for design of antiSARS drugs. Science 300:1763-1767;2003.

6 Baker SC, Yokomori K, Dong S, Carlisle R, Gorbalenya AE, Koonin EV, Lai MMC. Identification of the catalytic sites of a papain-like cystein proteinase of murine coronavirus. J Virol 67:6056-6063;1993.

7 Ballesteros ML, Sanchez CM, Enjuanes L. Two amino acid changes at the $\mathrm{N}$-terminus of transmissible gastroenteritis coronavirus spike protein result in the loss of enteric tropism. Virology 227:378-388; 1997

8 Baric RS, Fu K, Schaad MC, Stohlman SA. Establishing a genetic recombination map for murine coronavirus strain A59 complementation groups. Virology 177:646-656;1990.

9 Baric RS, Sullivan E, Hensley L, Yount B, Chen W. Persistent infection promotes crossspecies transmissibility of mouse hepatitis virus. J Virol 73:638-649;1999.

10 Baric RS, Yount B, Hensley L, Peel SA, Chen W. Episodic evolution mediates interspecies transfer of a murine coronavirus. J Virol 71: 1946-1955;1997.

II Bos ECW, Luytjes W, van der Meulen H, Koerten HK, Spaan WJM. The production of recombinant infectious DI-particles of a murine coronavirus in the absence of helper virus. Virology 218:52-60;1996.

12 Brierley I, Boursnell MEG, Binns MM, Bilimoria $\mathrm{B}, \mathrm{Blok} \mathrm{VC}$, Brown TDK, Inglis SC. An efficient ribosomal frame-shifting signal in the polymerase-encoding region of the coronavirus IBV. EMBO J 6:3779-3785;1987.

13 Burks JS, De Vald BL, Jankovsky LD, Gerdes JC. Two coronaviruses isolated from central nervous system tissue of two multiple sclerosis patients. Science 209:933-934;1980.

14 Casais R, Thiel V, Siddell SG, Cavanagh D, Britton P. Reverse genetics system for the avian coronavirus infectious bronchitis virus. J Virol 75:12359-12369;2001.

15 Charley $B$, Laude $\mathbf{H}$. Induction of alpha interferon by transmissible gastroenteritis coronavirus: role of transmembrane glycoprotein E1. J Virol 62:8-11;1988.
16 Chouljenko VN, Kousoulas KG, Lin X, Storz J. Nucleotide and predicted amino acid sequences of all genes encoded by the $3^{\prime}$ genomic protion $(9.5 \mathrm{~kb})$ of respiratory bovine coronaviruses and comparisons among respiratory and enteric coronaviruses. Virus Genes 17:33-42; 1998.

17 Corapi WV, Olsen CW, Scott FW. Monoclonal antibody analysis of neutralization and antibody-dependent enhancement of feline infectious peritonitis virus. J Virol 66:6695-6705; 1992.

18 de Groot RJ, Van Leen RW, Dalderup MJM, Vennema H, Horzinek MC, Spaan WJM. Stably expressed FIPV peplomer protein induces cell fusion and elicits neutralizing antibodies in mice. Virology 171:493-502;1989.

19 de Haan CA, Masters PS, Shen X, Weiss S, Rottier PJ. The group-specific murine coronavirus genes are not essential, but their deletion, by reverse genetics, is atteruating in the natural host. Virology 296:177-189;2002.

20 Delmas B, Gelfi JL, Haridon R, Vogel LK, Sjostrom H, Noren O, Laude H. Aminopeptidase $\mathrm{N}$ is a major receptor for the entero-pathogenic coronavirus TGEV. Nature 357:417420;1992.

21 Deregt D, Babiuk LA. Monoclonal antibodies to bovine coronavirus: Characteristics and topographical mapping of neutralizing epitopes on the E2 and E3 glycoproteins. Virology 161 : 410-420;1987.

22 Ding JW, Ning Q, Liu MF, Lai A, Leibowitz J, Peltekian KM, Cole EH, Fung LS, Holloway C, Marsden PA, Yeger H, Phillips MJ, Levy GA. Fulminant hepatic failure in murine hepatitis virus strain 3 infection: tissue-specific expression of a novel fg 12 prothrombinase. J Virol 71 : 9223-9230;1997. Erratum in J Virol 72:3504; 1997.

23 Domingo E, Holland J, Biebricher C, Eigen M. Quasi-species: the concept and the word. In Gibbs A, Calisher CH, Garcia-Arenal F (eds). Molecular Basis of Virus Evolution. Cambridge, Cambridge University Press, 181-191; 1995.

24 Drosten C, Gunther S, Preiser W, van der Werf $\mathrm{S}$, Brodt HR, Becker $\mathrm{S}$, Rabenau H, Panning M, Kolesnikova L, Fouchier RA, Berger A, Burguiere AM, Cinatl J, Eickmann M, Escriou N, Grywna K, Kramme S, Manuguerra JC, Muller S, Rickerts V, Sturmer M, Vieth S, Klenk HD, Osterhaus AD, Schmitz H, Doerr HW. Identification of a novel coronavirus in patients with severe acute respiratory syndrome. N Engl J Med 348:1967-1976;2003.

25 Fouchier RA, Kuiken $T$, Schutten $M$, van Amerongen $G$, van Doornum GJ, van den Hoogen BG, Peiris M, Lim W, Stohr K, Osterhaus AD. Aetiology: Koch's postulates fulfilled for SARS virus. Nature 423:240;2003.
26 Gallagher TM, Escarmis C, Buchmeier MJ. Alteration of the $\mathrm{pH}$ dependence of coronavirusinduced cell fusion: effect of mutations in the spike glycoprotein. J Virol 65:1916-1928; 1991.

27 Godet M, Grosclande J, Delmas B, Laude H. Major receptor-binding and neutralization determinants are located within the same domain of the transmissible gastroenteritis virus (cor onavirus) spike protein. J Virol 68:8008-8016; 1994.

28 Gombold JL, Hingley ST, Weiss SR. Fusiondefective mutants of mouse hepatitis virus A59 contain a mutation in the spike protein cleavage signal. J Virol 67:4504-4512:1993.

29 Gorbalenya AE, Koonin EV, Donchencko AP, Blinov VM. Coronavirus genome: prediction of putative functional domains in the nonstructural polyprotein by comparative amino acid sequence analysis. Nucleic Acids Res 17:4847 $4861 ; 1989$.

30 Gosert R, Kanjanahaluethai A, Egger D, Bienz K. Baker SC. RNA replication of mouse hepatitis virus takes place at double-membrane vesicles. J Virol 76:3697-3708;2002.

30a Guan Y, Zheng BJ, He YQ, Liu XL, Zhuang ZX, Cheung CL, Luo SW, Li PH, Zhang LJ, Guan YJ, Butt KM, Wong KL, Chan KW, Lim W, Shortridge KF, Yuen KY, Peiris JS, Poon LL. Isolation and characterization of viruses related to the SARS coronavirus from animals in southern China. Science 302:276-278;2003.

31 Guy JS, Breslin JJ, Breuhaus B, Vivrette S, Smith LG. Characterization of a coronavirus isolated from a diarrheic foal. J Clin Microbiol 38:4523-4526;2000.

32 Haijema BJ, Volders H, Rottier PJM. Switching species tropism: an effective way to manipulate the feline coronavirus genome. J Virol 77: 4528-4538;2003.

33 Herold J, Siddell SG, Gorbalenya AE. A human RNA viral cysteine proteinase that depends upon a unique $\mathrm{Zn}^{2+}$-binding finger connecting the two domains of a papain-like fold. J Biol Chem 274:14918-14925;1999.

34 Herrewegh AA, Mahler M, Hedrich HJ, Egberink HF, Horzinek MC, Rottier PJ, de Groot RJ. Persistence and evolution of feline coronavirus in a closed cat-breeding colony. Virology 234:349-363;1997.

35 Herrewegh AAPM, Smeenk I, Horzinek MC, Rottier PJM, de Groot RJ. Feline coronavirus type II strains $79-1683$ and $79-1146$ originate from a double recombination between feline coronavirus type I and canine coronavirus. IJ Virol 72:4508-4514;1998.

36 Kamahora T, Soe LH, Lai MMC. Sequence analysis of nucleocapsid gene and leader RNA of human coronavirus OC43. Virus Res 12:19:1989.

37 Kanjanahaluethai A, Baker SC. Identification of mouse hepatitis virus papain-like proteinase 2 activity. J Virol 74:7911-7921;2000. 
38 Kaye HS, Marsh HB, Dowdle WR. Seroepidemiologic survey of coronavirus (strain $O C$ 43) related infections in a children's population. Am J Epidemiol 94:43-49;1971.

39 Klumperman J, Locker JK, Meijer A, Horzinek MC, Geuze HJ, Rottier PJM. Coronavirus M proteins accumulate in the Golgi complex beyond the site of virion budding. $\mathrm{J}$ Virol 68 : 6523-6534;1994.

40 Knobler RL, Haspel MV, Oldstone MBA. Mouse hepatitis virus type 4 (JHM strain)induced fatal central nervous system disease. I. Genetic control and the murine neuron as the susceptible site of disease, J Exp Med 153:832$843 ; 1981$.

41 Ksiazek TG, ERdman D, Goldsmith CS, Zaki SR, Peret T, Emery S, Tong S, Urbani C, Comer JA, Lim W, Rollin PE, Dowell SF, Ling AE, Humphrey CD, Shieh WJ, Guarner J, Paddock CD, Rota P, Fields B, DeRisi J, Yang JY, Cox N, Hughes JM, LeDuc JW, Bellini WJ, Anderson LJ, SARS Working Group. A novel coronavirus associated with severe acute respiratory syndrome. N Engl J Med 348:1953-1966; 2003.

42 Kubo H, Yamada YK, Taguchi F. Localization of neutralizing epitopes and the receptor-binding site within the amino-terminal 330 amino acids of the murine coronavirus spike protein. J Virol 68:5403-5410;1994

43 Kuo L, Masters PS. The small envelope protein is not essential for murine coronavirus replication. J Virol 77:4597-4608;2003.

44 Kusters JG, Jager EJ, Niesters HG, van der Zeijst BA. Sequence evidence for RNA recombination in field isolates of avian coronavirus infectious bronchitis virus. Vaccine 8:605-608; 1991.

45 Ladman BS, Pope CR, Ziegler AF, Swieczkowski T, Callahan CJ, Davison S, Gelb J Jr. Protection of chickens after live and inactivated virus vaccination against challenge with nephropathologenic infectious bronchitis virus PA/Wolgemuth/98. Avian Dis 46:938-944; 2002.

46 Lai MMC. Genetic recombination in RNA viruses. Curr Top Microbiol Immunol 176:21$32 ; 1992$.

47 Lai MMC. Recombination and its evolutionary effects on viruses with RNA genomes. In: Gibbs A, Calisher CH, Garcia-Arenal F (eds). Molecular Basis of Virus Evolution. Cambridge, Cambridge University Press, 119-132; 1995.

48 Lai MMC, Cavanagh D. The molecular biology of coronaviruses. Adv Virus Res 48:1-100; 1997.

49 Lai MMC, Holmes KV. Coronaviridae and their replication. In: Knipe D, Howley $\mathrm{P}$ (eds). Fields' Virology. Philadelphia, Lippincott, Williams \& Wilkins;2001.

50 Laude H. Porcine respiratory coronavirus: molecular features and virus-host interactions. Vet Res 24:125-150;1993.

51 Lavi E, Wang Q, Weiss SR, Gonatas NK. Syncytia formation induced by coronavirus infection is associated with fragmentation and rearrangement of the Golgi apparatus. Virology 221:325-334;1996.
52 Leparc-Goffart I, Hingley ST, Chua MM, Phillips J, Lavi E, Weiss SR. Targeted recombination within the spike gene of murine coronavirus mouse hepatitis virus A59:Q159 is a determinant of hepatotropism. J Virol 72:9628$9636 ; 1998$.

53 Liu C, Xu HY, Liu DX. Induction of caspasedependent apoptosis in cultured cells by the avian coronavirus infectious bronchitis virus. I Virol 75:6402-6409;2001.

54 Luytjes W, Bredenbeek PJ, Noten AFH, Horzinek MC, Spaan WJM. Sequence of mouse hepatitis virus A59 mRNA 2:Indications for RNArecombination between coronavirus and influenza $C$ virus. Virology 166:41.5-422;1988.

55 Marra MA, Jones SJ, Astell CR, Holt RA Brooks-Wilson A, Butterfield YS, Khattra $J$ Asano JK, Barber SA, Chan SY, Cloutier A, Coughlin SM, Freeman D, Girn N, Griffith OL, Leach SR, Mayo M, McDonald H, Montgomery SB, Pandoh PK, Petrescu AS, Robertson AG, Schein JE, Siddiqui A, Smailus DE, Stott JM, Yang GS, Plummer F, Andonov A, Artsob H, Bastien N, Bernard K, Booth TF, Bowness D, Czub M, Drebot M, Fernando L, Flick R, Garbutt M, Gray M, Grolla A, Jones S, Feldmann H, Mevers A, Kabani A, Li Y, Normand S, Stroher U, Tipples GA, Tyler S, Vogrig $\mathrm{R}$, Ward D, Watson B, Brunham RC, Krajden M, Petric M, Skowronski DM, Upton C, Roper RL. The genome sequence of the SARS-associated coronavirus. Science 300: 1399-1404;2003.

56 Marten NW, Stohlman SA, Bergmann CC. MHV infection of the CNS: mechanisms of immune-mediated control, Viral Immunol 14: $1-18 ; 2001$.

57 McIntosh K, Kapikian AZ, Turner HC, Hartley JW, Parrott RH, Chanock RM. Seroepidemiologic studies of coronavirus infection in adults and children. Am J Epidemiol 91:585592;1970.

58 Nicholls JM, Poon LLM, Lee KC, Ng WF, Lai ST, Leung CY, Chu CM, Hui PK, Mak KL Lim W, Yan KW, Chan KH, Tsang NC, Guan Y, Yuen KY, Peiris JSM. Lung pathology of fatal severe acute respiratory syndrome. Lancet 361:1773-1778;2003.

59 Ning Q, Liu M, Kongkham P, Lai MM, Marsden PA, Tseng J, Pereira $B$, Belyavskyi $M$, Leibowitz J, Phillips MJ, Levy GA. The nucleocapsid protein of murine hepatitis virus type 3 induces transcription of the novel fg12 prothrombinase gene. $J$ Biol Chem 274:99309936;1999.

60 Normile D, Enserink M. SARS in China: Tracking the roots of a killer. Science 301:297299;2003.

61. Ortego J, Sola I, Almazan F, Ceriani JE, Riquelme C, Balasch M, Plana J, Enjuanes L. Transmissible gastroenteritis coronavirus gene 7 is not essential but influences in vivo virus replication and virulence. Virology 308:13-22; 2003.
62 Peiris JS, Lai ST, Poon LL, Guan Y, Yam LY, Lim W, Nichols J, Yee WK, Yan WW, Cheung MT, Cheng VC, Chan KH, Tsang DN, Yung RW, Ng TK, Yuen KY, SARS Study Group. Coronavirus as a possible cause of severe acute respiratory syndrome. Lancet 361:1319-1325; 2003.

63 Peng D, Koetzner CA, Masters PS. Analysis of second-site revertants of a murine coronavirus nucleocapsid protein deletion mutant and construction of nucleocapsid protein mutants by targeted RNA recombination. J Virol 69:3449 $3457 ; 1995$

64 Pratelli A, Tinelli A, Decaro N, Cirone F, Elia G, Roperto S, Tempesta M, Buonavoglia C Efficacy of an inactivated canine coronavirus vaccine in pups. New Microbiol 26:151-155 2003.

65 Risco C, Anton IM, Enjuanes L, Carrascosa JL. The transmissible gastroenteritis coronavirus contains a spherical core shell consisting of $\mathrm{M}$ and N proteins. J Virol 70:4773-4777;1996.

66 Rota PA, Oberste MS, Monroe SS, Nix WA Campagnoli R, Icenogle JP, Penaranda S, Bankamp B, Maher K, Chen MH, Tong S, Tamin A, Lowe L, Frace M, DeRisi JL, Chen Q, Wang D, Erdmann DD, Peret TC, Burns C, Ksiazek TG, Rollin PE, Sanchez A, Liffick S, Holloway $B$, Limor J, McCaustland K, Olsen-Rasmussen M, Fouchier R, Gunther S, Osterhaus $A D$ Drosten C, Pallansch MA, Anderson LJ, Bellini WJ. Characterization of a novel coronavirus associated with severe acute respiratory syndrome. Science 300:1394-1399;2003.

67 Ruan YJ, Wei CJ, Ee AL, Vega VB, Thoreau H Su ST, Chia HM, Ng P, Chiu KP, Lim L, Zhang T, Peng CK, Lin EO, Lee NM, Yee SL, Ng LF, Chee RE, Stanton LW, Long PM, Liu ET. Comparative full-length genome sequence analysis of 14 SARS coronavirus isolates and common mutations associated with putative origins of infection. Lancet 361:1779-1785 2003. Erratum in Lancet $361: 1832 ; 2003$.

68 Schiller JJ, Kanjanahaluethai A, Baker SC Processing of the coronavirus MHV-JHM polymerase polyprotein: Identification of precursors and proteolytic products spanning 400 kilodaltons of ORF1a. Virology 242:288-302; 1998.

69 Shi ST, Schiller JI, Kanjanahaluethai A, Baker $\mathrm{SC}$, Oh JW, Lai MMC. Colocalization and membrane association of murine hepatitis virus gene I products and de novo-synthesized viral RNA in infected cells. $J$ Virol 73:5957... 5969;1999.

70 Snijder EJ, Bredenbeek PI, Dobbe JC, Thiel V, Ziebuhr J, Poon LL, Guan $Y$, Rozanov $M$, Spaan WJ, Gorbalenya AE. Unique and conserved features of genome and proteome of SARS-coronavinus, an early split-off from the coronavirus group 2 lineage. J Mol Biol 331: 991-1004:2003.

71 Stewart NN, Mounir S, Talbot PI. Human coronavirus gene expression in the brains of multiple sclerosis patients. Virology 191:502-505; 1992. 
72 Thiel V, Herold J, Schelle B, Siddell SG. Viral replicase gene products suffice for coronavinus discontinuous transcription. J Virol 75:6676$6681 ; 2001$.

73 Tooze J, Tooze SA, Fuller SD. Sorting of progeny coronavirus from condensed secretory proteins at the exit from the trans-Golgi network of AtT20 cells. J Cell Biol 105:1215-1226:1987.

74 Underdahl NR, Mebus CA, Torres-Medina A. Recovery of transmissible gastroenteritis virus from chronically infected experimental pigs. Am J Vet Res 36:1473-1476;1975.

75 Vennema H, Godeke GJ, Rossen JWA, Voorhout WF, Horzinek MC, Opstelten DJE, Rottier PJM. Nucleocapsid-independent assembly of coronavirus-like particles by co-expression of viral envelope protein genes. EMBO J 15 : 2020-2028;1996.

76 Wang L, Junker D, Collison EW. Evidence of natural recombination within the S1 gene of the infectious bronchitis virus. Virology 192 : $710-716 ; 1993$.
77 Weismiller DG, Sturman LS, Buchmeier MJ, Fleming JO, Holmes KV. Monoclonal antibodies to the peplomer glycoprotein of coronavirus mouse hepatitis virus identify two subunits and detect a conformational change in the subunit released under mild alkaline conditions. J Virol 64:3051-3055;1990.

78 Weiss RC, Scott FW. Antibody-mediated enhancement of disease in feline infectious peritonitis: comparisons with dengue hemorrhagic fever. Comp Immunol Microbiol Infect Dis 4: 175-189;1981.

79 Williams RK, Jiang GS, Holmes KV. Receptor for mouse hepatitis virus is a member of the carcinoembryonic antigen family of glycoproteins. Proc Natl Acad Sci USA 88:5533-5536; 1991.
80 Yeager CL, Ashumn RA, Williams RK, Cardellichio CB, Shapiro LH, Look AT, Holmes KV. Human aminopeptidase $\mathrm{N}$ is a receptor for human coronavirus 229E. Nature 357:420422;1992.

81 Yount B, Denison MR, Weiss SR, Baric RS. Systematic assembly of a full-length infectious eDNA of mouse hepatitis virus strain A59. J Virol 76:11065-11078;2002.

82 Zhang X, Herbst W, Kousoulas KG, Storz J. Biological and genetic characterization of a hemagglutinating coronavirus isolated from a diarrhoeic child. I Med Virol 44:152-161; 1994.

83 Ziebuhr $\mathbf{J}$, Siddell SG. Processing of the human coronavirus $229 \mathrm{E}$ replicase polyproteins by the virus-encoded $3 \mathrm{C}$-like proteinase: Identification of proteolytic products and cleavage sites common to ppla and pplab. J Virol 73:177$185 ; 1999$. 